\title{
A UTILIZAÇÃO DE ANIMAIS NOS CONTOS HISTÓRICOS DE AKUTAGAWA ${ }^{(1)}$
}

\author{
Luiza Nana Yoshida
}

Após ter lido $\underline{\text { Rashômon, }}$ um dos contos mais conhecidos de Ryûnosuke Akutakawa (1892-1927), a minha atenção foi voltada para a utilização de animais neste conto. Desejando saber até que ponto esta utilização seria importante, escolhi mais três contos do mesmo autor, que pertencem à mesma época de Rashômon, para comparar ou contrastar os usos em cada um deles.

De maneira geral, as obras de Akutagawa podem ser englobadas em três grupos: 1) obras baseadas em obras clássicas (principalmente $\mathbf{K o n j a -}$ ku Monogatari, obra clássica do século XII); 2) obras que têm como cena de fundo a era Edo (1603-1867); 3) novelas modernas. Os quatro contos em questão pertencem ao grupo 1 .

São os seguintes os contos que tentarei analisar do ponto de vista da utilização de animais:

1 - Rashômon (1915)

2 - Hana (1916)

3 - Imogayu (1916)

4 - $\underline{\text { Chûtô }}$ (1917)

Antes de entrar na análise propriamente dita, vale colocar aqui o resumo de cada um deles.

\section{Rashômon}

Depois de ter sido despedido de um emprego de muitos anos, devido à difícil época ora enfrentada pelo Japão, o protagonista, embora achando que para continuar a viver seria necessário roubar, não tivera ainda a coragem de tomar tal atitude. Nessa indecisão

(1) Este artigo tem por base um trabalho que fiz quando estudante, acrescido de algumas correções necessárias e espero, de algumas idéias novas que amadureceram naturalmente no decorrer dos anos. 
ele espera a chuva passar, sentado no portal Rashômon.

Resolvido a descansar na parte superior do portal, o infeliz sobe alguns degraus da escada. A cena que aí assiste, deixa-o, a princípio, extremamente chocado. Ele vê, no meio de muitos cadáveres, uma velha a arrancar, fio por fio, os cabelos de um deles. Esquecendo-se do fato de que há pouco, ele próprio estivera pensando em se tornar um ladrão, o protagonista sente ódio em relação ao ato da veIha.

Depois de ouvir o motivo que a levara a tomar tal atitude, isto é, o seu ato justificava-se pelo fato de ela praticá-lo para a sua sobrevivência, o protagonista adquire enfim a coragem que há instantes não tivera: toma as vestes da velha, deixando-a no desamparo e desaparece noite adentro.

\section{$\underline{\text { Hana }}$}

O personagem deste conto sofria há vários anos por causa de um problema: ele possuía um nariz descomunal (aproximadamente 15-18 cm). Assim, o seu nariz havia se tornado alvo de constantes comentários irônicos.

Depois de várias tentativas frustradas para diminuir o tamanho do seu nariz, surge um indivíduo que diz possuir um meio simples de fazê-lo, e realmente, aplicando o seu método, o nariz diminui de tamanho, adquirindo um aspecto normal.

O fato de possuir agora um nariz normal deveria ter acabado com os seus problemas. No entanto, a descoberta de uma verdade faz com que o personagem comece a odiar o fato de o seu nariz ter diminuído de tamanho: o egoísmo humano. A partir do momento em que um indivíduo do qual sentiam pena consegue sair da sua desgraça, as pessoas ficam insatisfeitas e sentem a necessidade de arrastá-lo de novo à infelicidade. E era exatamente isso que o personagem sentia quando as pessoas riam agora, ainda mais do que antes, quando tinha o nariz descomunal, ao olharem para o seu rosto.

Numa certa manhã, depois de passado alguns dias, o personagem começa a sentir coceiras no nariz e percebe que este voltara ao tamanho que tinha antes. Ao ver de novo o seu nariz descomunal, ele sente uma estranha alegria, a mesma que sentira quando o seu nariz adquirira um aspecto normal.

\section{$\underline{\text { Imogayu }}$}

Havia dentre os subordinados que serviam ao Regente da épo- 
ca, Fujiwara-no-Mototsune, um, conhecido apenas pelo seu posto, Goi, ridicularizado por todos, por causa do seu aspecto insignificante, da sua fraqueza e da sua covardia. Para defini-lo, nada melhor que uma frase que encontramos a certa altura do conto: "Assim como não se vê o ar, também a existência de Goi não deve perturbar os olhos..."

Este homem desprezado e ignorado por todos tinha uma única alegria, um único sonho: poder, um dia, deliciar-se com imogayu (uma papa doce feita com um tipo de batata) até enjoar.

Quando se encontra diante dessa possibilidade, no entanto, Goi hesita: ele não quer mais que o seu desejo seja realizado tão rapidamente e percebe que, embora desprezado por todos ele era muito feliz quando guardava secretamente e com carinho um desejo: o de querer enjoar de imogayu.

\section{Chûtô}

Numa época em que o homem vive num mundo onde não existe praticamente lugar para o sentimento humano, o autor mostra o relacionamento entre dois irmãos, Tarô e Jirô, apaixonados pela mesma mulher, Shakin, chefe de um grupo de bandoleiros, uma mulher fria, incapaz de demonstrar qualquer sentimento humano.

Tarô e Jirô, embora cientes da perversidade de Shakin e conhecedores do amor que cada um deles sente por ela, não conseguem se libertar dela e chegam até a desejar a morte um do outro. No final, entretanto, vence a forte ligação fraternal que os une e que os leva a matar Shakin.

Lido os contos, procurei ver se havia algum ponto em comum no que se refere ao uso de animais e pude constatar que em alguns deles o uso é bastante frequiente e em outros, não. Fazendo o levantamento dos usos de animais presentes nos contos, separei-os da seguinte forma: os animais usados como tais e as comparações feitas com eles, e montei os seguintes quadros: 
QUADRO DOS ANIMAIS UTILIZADOS COMO TAIS

\begin{tabular}{|c|c|c|c|c|c|}
\hline & Rashômon & Hana & Imogayu & Chûtô & Total \\
\hline andorinha & & & & 2 & 2 \\
\hline aranha & 1 & & & 1 & 2 \\
\hline boi & & & & 1 & 1 \\
\hline cão & & 2 & 3 & 58 & 63 \\
\hline cavalo & & & 20 & 31 & 51 \\
\hline cobra & 1 & & & 8 & 9 \\
\hline coelho & & & & 1 & 1 \\
\hline corvo & 3 & & 1 & 2 & 6 \\
\hline cuco & & & & 2 & 2 \\
\hline escaravelho & & & & 1 & 1 \\
\hline falcão & & & & 1 & 1 \\
\hline falcão siberiano & & & & 1 & 1 \\
\hline formiga & & & & 1 & 1 \\
\hline galo & & & & 1 & 1 \\
\hline gato & & & & 6 & 6 \\
\hline grilo & 2 & & & 1 & 3 \\
\hline$h a e^{(1)}$ & & & & 1 & 1 \\
\hline lagarto & & & & 1 & 1 \\
\hline macaco & & & & 1 & 1 \\
\hline morcego & & & & 1 & 1 \\
\hline mosca & & & & 1 & 1 \\
\hline pernilongo & & & & 1 & 1 \\
\hline raposa & 1 & & 18 & 2 & 21 \\
\hline sapo & & & & 1 & 1 \\
\hline sekirei $^{(2)}$ & & & 1 & & 1 \\
\hline texugo japonês & 1 & & & & 1 \\
\hline varejeira & & & & 3 & 3 \\
\hline verme & & & & 1 & 1 \\
\hline rato & & 1 & & & 1 \\
\hline Total & 9 & 3 & 43 & 131 & 186 \\
\hline \multicolumn{6}{|c|}{$\begin{array}{l}\text { Obs.: Os números indicam a frequiência com que aparecem em cada conto. } \\
\text { (1) Pequeno peixe de água doce (Leuciscus macropus). } \\
\text { (2) Pássaro da família dos motocilídeos (Motacillidae) }\end{array}$} \\
\hline
\end{tabular}




\section{QUADRO DAS COMPARAÇÕES FEITAS COM ANIMAIS}

\begin{tabular}{|c|c|}
\hline Rashômon & $\begin{array}{l}\text { - são abandonados como cães } \\
\text { - encolhendo o corpo como um gato } \\
\text { - passos silenciosos como os de uma lagartixa } \\
\text { - como quando se cata o piolho do filhote de macaco } \\
\text { - velha que se parecia com um macaco } \\
\text { - braços só com pele e osso como os pés de uma galinha } \\
\text { - olhos aguçados como os das aves de rapina } \\
\text { - voz semelhante ao crocitar do corvo } \\
\text { - voz semelhante ao coaxar do sapo }\end{array}$ \\
\hline$\underline{\text { Hana }}$ & $\begin{array}{l}\text { - coça como se tivesse sido picado por uma pulga } \\
\text { - parecia um passarinho depenado e assado inteiro } \\
\text { - formato semelhante à ponta das asas das aves }\end{array}$ \\
\hline Imogayu & $\begin{array}{l}\text { - não desperta sequer a atenção que uma mosca despertaria } \\
\text { - vida como a de um cão } \\
\text { - andar de um boi magro } \\
\text { - costas curvadas como as de um gato } \\
\text { - como se estivesse espantando uma mosca } \\
\text { - perambula como um cão peludo sem dono }\end{array}$ \\
\hline Chûtô & $\begin{array}{l}\text { - que lembra a anca do sapo } \\
\text { - rosto que faz lembrar o sapo } \\
\text { - voz semelhante ao do corvo } \\
\text { - semelhante ao macaco } \\
\text { - voz semelhante ao chiar do rato } \\
\text { - mais cruel do que um animal } \\
\text { - faz lembrar um ganso negro } \\
\text { - coração como o de um animal } \\
\text { - agilidade de gato } \\
\text { - que não difere da asa do corvo } \\
\text { - obediente como um cão } \\
\text { - olhos aguçados como os de um gato selvagem } \\
\text { - algo que picava como um escorpião } \\
\text { - como um coelho em fuga } \\
\text { - como o bater das asas de um morcego } \\
\text { - como um corvo destituído das suas penas } \\
\text { - um urro como o de um animal } \\
\text { - como o bater das asas de um gafanhoto } \\
\text { - como aquele inseto } \\
\text { - picando como um pernilongo } \\
\text { - como um sapo sem pele } \\
\text { - semelhante às tripas expostas de um peixe }\end{array}$ \\
\hline
\end{tabular}


Baseado nos quadros acima gostaria, então, de verificar de que maneira os animais são utilizados nesses contos.

Inicialmente levando-se em conta o número de usos, torna-se possível agrupar os contos da seguinte maneira:

a) animais utilizados como tais:

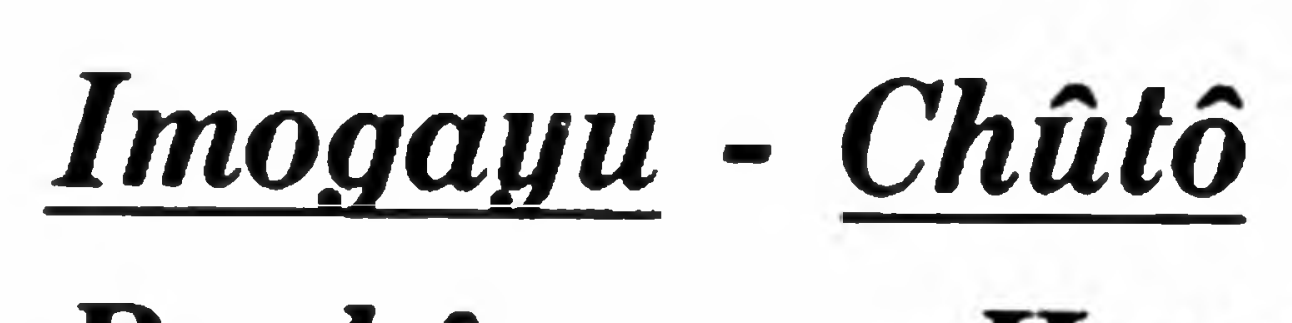

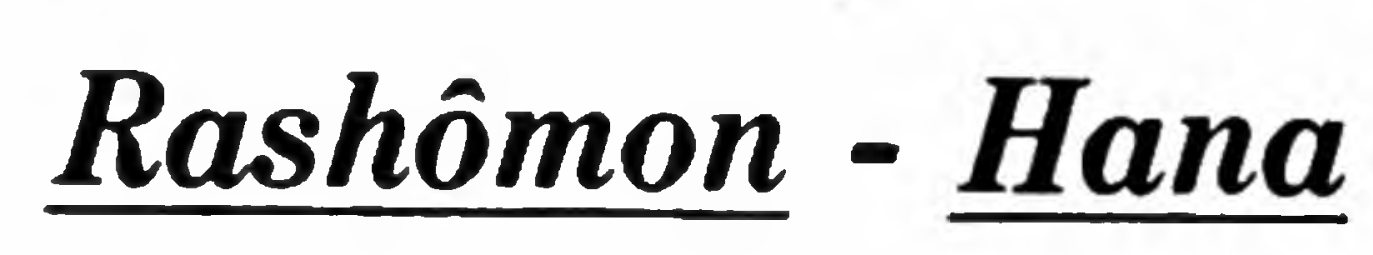

b) comparações feitas com animais: $\underline{\text { Rashômon - Chûtô }}$

\section{$\underline{\text { Hana }}-\underline{\text { Imogayu}}$}

Esses agrupamentos talvez possam ser explicados pelos pontos em comum que os contos possuem entre si. Senão vejamos:

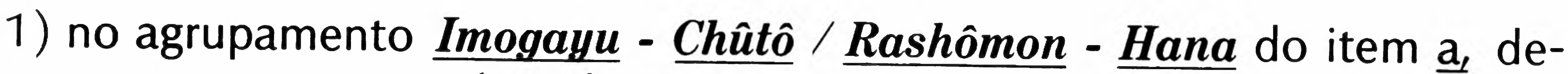
vemos nos ater ao fato de que Imogayu e Chûtô têm como cenário predominante o ambiente exterior, ou seja, o ambiente mais propício para o aparecimento e a ação de animais como o cão, o cavalo, a raposa, etc. que conforme se vê no quadro, aparecem em maior número. A presença de animais torna-se então menos frequiente em $\underline{\text { Rashômon }}$ - $\underline{\text { Hana }}$, pois o cenário predominante é o ambiente interno: $\underline{\text { Rasho- }}$ $\underline{\text { mon }}=$ interior do portal e $\underline{\text { Hana }}=$ interior do templo. Os $\underline{\text { poucos }}$ animais que aparecem nesses contos são geralmente animais de pequeno porte ou insetos normalmente encontrados dentro de casa, como o rato e a aranha ou animais que poderiam ser encontrados dentro de casa como a cobra e o grilo.

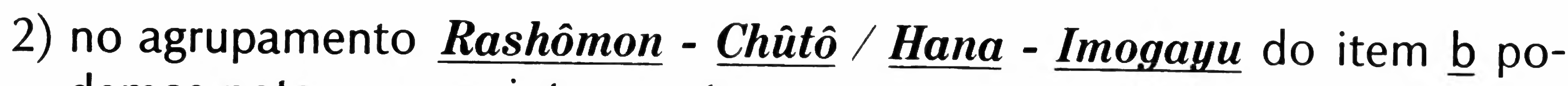
demos notar os seguintes pontos em comum:

Rashômon - Chûtô

- as duas histórias relatam acontecimentos de uma mesma época, ou seja, uma época negra repleta de catástrofes (incêndio, tornado, inundação, seca e as consequiências naturais, fome e epidemia) pela qual passou o Japão no final da era Heian (século XIII), onde cada qual só tinha condições de pensar em si próprio para poder sobreviver;

- os protagonistas de ambas as histórias têm em comum o ato de roubar. 
Hana - Imogayu

- os protagonistas dos dois contos possuem um fato em comum: são portadores de defeitos, um físico e o outro, se assim podemos dizer, defeito espiritual, ou seja, o protagonista de $\underline{\text { Hana }}$ possui um nariz descomunal e o protagonista de Imogayu é um homem extremamente fraco, covarde até medíocre.

Assim sendo, em Rashômon e $\underline{\text { Chûtô, }}$, as comparações com animais tornam-se importantes, na medida em que servem para fazer a caracterização exterior dos personagens. E para que essas caracterizações adquiram maior relevância há que se levar em conta o momento histórico dos dois contos: o Japão passava por um período extremamente difícil, castigado por sucessivas catástrofes. Devido ao longo período de desgraças, o único modo que se tinha para continuar vivendo era roubando os semelhantes. Era uma época em que os objetos valiosos eram trocados por um punhado de comida ou um pedaço de madeira que pudesse servir de lenha.

Por não ter mais condições de recolher os mortos que aumentavam a cada dia, era muito comum encontrar-se cadáveres espalhados pelas ruas. Rashômon, o principal portal para entrar na capital, Quioto, havia se tornado uma espécie de depósito de cadáveres, não lembrando em nada aquele magnífico portal que simbolizava a capital nos seus dias de glória. O que se tinha, portanto, é um ambiente sombrio, fétido e mórbido. Rashômon e Chûtô são dois episódios de uma mesma época (século XIII) e de um mesmo espaço (Quioto, a capital da época).

Nesse ambiente negro, a caracterização feita através de comparações com animais acaba integrando os personagens nesse ambiente (pela própria identificação homem - animal) e adquire maior peso.

Rashômon

Os protagonistas: um jovem serviçal dispensado do seu emprego e uma velha.

Jovem - encolhendo o corpo como um gato

- passos silenciosos como os de um lagartixa

Velha - começou a arrancar os fios desses cabelos longos, um por um, como quando se cata o piolho do filhote de macaco

- velha que se parecia com um macaco 
- braços só com pele e osso, como os pés de uma galinha

- olhos aguçados como os das aves de rapina

- voz semelhante ao crocitar do corvo

- voz semelhante ao coaxar do sapo

Através dessas comparações podemos levantar os seguintes pontos:

Jovem - as comparações com animais são utilizadas para caracterizar as suas ações, através de animais que têm em comum a sua agilidade (gato) e o seu andar leve e silencioso (lagartixa), peculiaridades imprescindíveis para um ladrão.

Velha - as comparações com animais são utilizadas para caracterizar predominantemente o seu aspecto físico, mas também nos mostram porque uma velha ainda continuava viva numa época tão dura onde os idosos tinham menos chances de sobreviver.

Observando inicialmente o uso da palavra rôba = "muIher velha", cabe notar que esta palavra tem o sentido mais específico de "mulher que tendo envelhecido em demasia, salta à vista somente a sua senilidade(2)", onde já encontramos uma primeira imagem da velha.

Fisicamente temos a imagem de um macaco, animal que mais se assemelha ao homem, podendo ser tomado, portanto, como uma figura caricaturesca do próprio homem, além de nos dar a impressão de um rosto envelhecido devido às suas rugas naturais.

Simbolicamente o macaco ou "os símios têm um sentido geral de força inferior, sombra, atividade inconsciente ...(3)", além de ser comumente utilizado como adjetivo de algo feio.

Neste sentido não nos parece inadequado identificarmos a velha de Rashômon com a figura simbólica do macaco no que concerne ao sentido ativo (força, atividade) encontrado nesse animal, o que explique, talvez, o fato de ela continuar viva numa época tão dura.

Essa figura caricaturesca e senil é reforçada ainda pelo seu gesto: arrancava os fios de cabelo de um cadáver como quan-

(2) Dicionário da Língua Japonesa Shinmeikai org. por Kyôsuke Kindaichi et allii. Tóquio, Ed. Sanseidô, 1974.

(3) Dicionário de Símbolos - Juan Eduardo Cirlot (Trad. de Rubens Eduardo Ferreira Frias). S.P., Ed. Moraes, 1984. 
do se cata o piolho do filhote de macaco, um gesto bastante desajeitado, mas ao mesmo tempo realizado com desvelo.

Quanto à caracterização exterior encontramos ainda a sua figura esquelética, reflexo de uma época de grande penúria e da avançada idade: "braços só com pele e osso como os pés de uma galinha", imagem também um tanto repugnante se considerarmos que o pé seja talvez a parte mais desagradável da galinha, visualmente. Quanto à sua voz semelhante ao crocitar do corvo e semelhante ao coaxar do sapo se ajusta à descrição até agora feita, já que o crocitar do corvo muitas vezes vem ligado à idéia de mau agouro e o sapo, simbolicamente indica "o aspecto inverso e infernal da rã (4)", tendo assim os dois animais um sentido negativo e as suas vozes nos soam um tanto sinistros.

Complementando a descrição da velha temos: olhos aguçados como os das aves de rapina, a única descrição que destoa na senil figura da velha. A impressão que temos é a de que o autor tenta resumir nos seus olhos tudo aquilo que a vida já havia lhe tirado externamente: a sua energia interior e aquilo que existe de mais forte no ser humano, a força do viver que sustenta o homem nas horas mais difíceis da sua vida.

\section{Chûtô}

Em $\underline{\text { Chûtô, }}$ a caracterização da velha mãe de Shakin assemelha-se muito à figura da velha de $\underline{\text { Rashômon: }}$

- algo semelhante a um macaco

- rosto que faz lembrar um sapo

- voz semelhante a do corvo

Contrastando com essa figura feia e senil surge Shakin descrita da seguinte maneira:

- voz semelhante ao chiar do rato

- coração como o de um animal

- agilidade de um gato

- (cabelo) que não difere da asa de um corvo (cor negra)

(4) Idem a (3). 
- olhos aguçados como os de um gato selvagem

- (no interior das suas palavras havia) algo que picava como um escorpião

Através dessas comparações podemos montar uma imagem de Shakin: jovem, bela, sedutora e cruel. A sua juventude indicada pelos gestos ágeis (agilidade de gato) e olhos vivos (como os de um gato selvagem); sua beleza representada pelos cabelos negros (que não diferem com a asa do corvo), símbolo da beleza feminina na época; o seu poder de sedução indicado pela sua voz dengosa (semelhante ao chiar do rato); a sua crueldade e frieza pela inexistência de sentimento (coração como o de um animal) ou palavras venenosas (que picava como um escorpião).

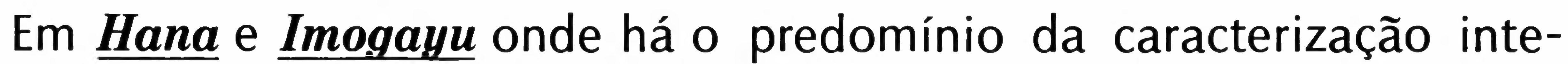
rior não se encontram muitas comparações com animais. Os personagens em si representam figuras que se distanciam, de certa maneira, do homem comum e nos fazem lembrar certos animais. Em Hana, o personagem é portador de um nariz fora do comum, muito longo (lembrando-nos a tromba de um elefante) e em Imogayu deparamo-nos com um personagem submisso e medroso (como um cão vadio assustado), cuja existência parecia ser nula de tão insignificante.

Assim sendo, as poucas comparações que aparecem são utilizadas, no caso de $\underline{\text { Hana }}$, para qualificar o longo nariz do personagem:

- (o nariz) coca como se tivesse sido picado por uma pulga

- (o nariz) parecia um passarinho depenado e assado inteiro

e em Imogayu para ressaltar a insignificância e a pobre figura do personagem Goi:

- não desperta sequer a atenção que uma mosca despertaria

- (levava uma) vida como a de um cão

- como se estivéssemos vendo o andar de um boi magro puxando uma carroça

- (tinha) costas curvadas como as de um gato

- perambular como um cão peludo sem dono

donde podemos construir a imagem de Goi: fisicamente feio (costas curvadas como as de um gato), insignificante (não desperta sequer a atenção que uma mosca despertaria) e uma figura patética e medrosa (vendo o andar de um boi magro; vida como a de um cão; perambular como um cão peludo sem dono).

A utilização de animais é também importante para a caracterização

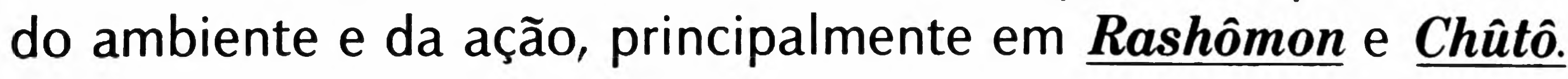


Rashômon

Ambiente de desolação e abandono

- Numa grande coluna, há um grilo parado

- Então aproveitando-se da desolação, moram aí raposas e texugos

- Mas por outro lado, ajuntaram-se, não se sabe de onde, muitos corvos

- O teto com teias de aranha por todos os cantos

Ação

\begin{tabular}{|c|c|c|}
\hline jovem & animal & movimento \\
\hline $\begin{array}{l}\text { - Está esperando a chuva } \\
\text { passar }\end{array}$ & - Um grilo está parado. & imobilidade \\
\hline $\begin{array}{l}\text { - O serviçal levanta-se } \\
\text { languidamente }\end{array}$ & - O grilo também foi para & movimento lento \\
\hline $\begin{array}{l}\text { - Espreita o aspecto da } \\
\text { parte de cima do portal }\end{array}$ & $\begin{array}{l}\text { - Espreita o aspecto de ci- } \\
\text { ma com o corpo encolhi- } \\
\text { do como um gato }\end{array}$ & $\begin{array}{l}\text { movimentos } \\
\text { cuidadosos }\end{array}$ \\
\hline $\begin{array}{l}\text { - Sobe até o último } \\
\text { degrau da escada }\end{array}$ & $\begin{array}{l}\text { - Com os passos silenciosos } \\
\text { como os de uma lagartixa }\end{array}$ & $\begin{array}{l}\text { movimentos } \\
\text { silenciosos }\end{array}$ \\
\hline
\end{tabular}

Como podemos perceber no quadro acima, cada movimento do jovem serviçal encontra-se ligado a um animal o que nos permite uma imagem visual mais nítida desta sequiência de cenas que lembram uma tomada cinematográfica.

\section{Chûtô}

\section{Ambiente fétido}

- Também a pequena cobra esmagada pela roda desse carro, esverdeando a carne no local do ferimento, estava a princípio sacudindo o rabo, mas num instante volvendo a barriga gordurosa para cima, deixou já de esboçar qualquer movimento.

- Se houver alguma coisa que possua uma gota mínima de umidade, nesta esquina da cidade, empoeirada por todos os cantos pelas poeiras deste calor fogoso, essa coisa é a água malcheirosa oriunda do ferimento dessa cobra. 
- Em meio a isso, vê-se somente o cadáver da cobra, fazendo brilhar, ainda mais, a gordura da barriga.

- Depois que os dois se separaram, as varejeiras que se juntaram sobre a citada cobra, soltando como sempre um leve ruído do bater das asas à luz do sol, ora voavam ora pousavam.

- Três ou quatro crianças da cidade, com a cobra pendurada na ponta de um galho, ao passarem pela cabana onde estava a doente, jogaram essa cobra sobre o seu rosto. A barriga verde $\mathrm{e}$ gordurosa caiu em cheio no rosto da mulher e, depois, o rabo molhado de um líquido putrefato pendeu queixo abaixo.

- E também alguns lagartos estavam horrendamente aderentes com os seus corpos pretos como fuligem, mas devem ter se assustado com os passos de Tarô, pois mesmo antes de sentirem a sua sombra, espalharam-se agitadamente pelos quatro cantos.

Ação

Encontramos maior ação em Chûtô exatamente na parte onde há a luta entre os homens e os animais; aliás, o autor dedica boa parte do conto para narrar essa luta. Vejamos um trecho dessa narração:

"Jirô veio descendo, embora sem essa intenção, aproximadamente 200 a 300 metros para o sul, brandindo a sua espada cheia de sangue e confrontando-se com dois samurais e três cães. Agora não há tempo de se preocupar com a segurança de Shakin. Os samurais atacam cerradamente confiando na sua superioridade numérica. Também os cães lançam-se, não se importando se pela frente ou por trás, levantando o dorso de pelos eriçados. A rua estava iluminada pela luz do luar, que, embora vaga, era clara o suficiente para não deixar que as espadas errassem o alvo.

Em meio a isso Jirô, cercado por homens e cães por todos os lados, luta desesperadamente. Para continuar a viver, de duas uma: matar o adversário ou ser morto por este. Junto com essa resignação veio aumentando, momento a momento, na sua alma, uma feroz coragem que ultrapassava os limites do senso comum.

Interceptando a espada do adversário e respondendo ao seu ataque, empurra prontamente os cães que tentam atacá-lo pelos pés. Ele pratica esses movimentos quase ao mesmo tempo. Não é só isso. Dependendo do caso, nesta hora, tem até que deter as presas dos cães que vêm por trás, puxando de volta a espada que investira contra o adversário.

Podemos ainda acrescentar que a utilização dos animais torna-se também importante na medida em que contribuem para enriquecer sen- 


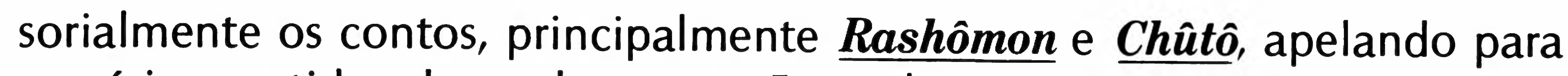
os vários sentidos do ser humano. Exemplos:

- visão - velha que se parecia com um macaco

- rosto que faz lembrar um sapo

- audição - passos silenciosos como os de uma lagartixa

- voz semelhante ao crocitar do corvo

- como o bater das asas de um morcego

- olfato - água malcheirosa oriunda do ferimento dessa cobra

- tato - que picava como um escorpião

- vem picando como um pernilongo

- como se tivesse sido picado pela pulga

Isto posto,podemos concluir que a utilização de animais torna-se importante em vários aspectos: caracterização dos personagens, do am-

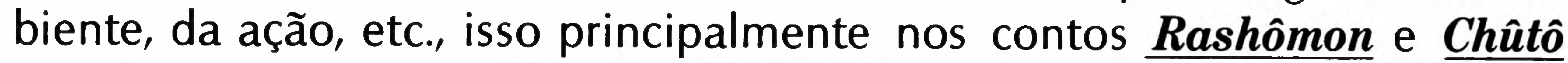
e em menor escala em Hana e Imogayu. Esta diferença, talvez, advenha do próprio fato de terem os dois grupos um caráter distinto. Quanto ao enfoque do autor, por exemplo, em Rashômon e Chûtô encontramos, principalmente a preocupação do autor em enfocar o conflito interno (roubar ou não roubar, matar ou não matar) dos personagens, envolvidos pelo ambiente que os cerca (época de grande desgraça). Já em Hana e Imogayu temos a focalização de problemas individuais e o ambiente que os cerca decorre da própria personalidade dos personagens. Em outras palavras, nos dois primeiros contos o ambiente atua efetivamente sobre os personagens e nos dois últimos, os personagens é que criam um determinado ambiente. Assim:

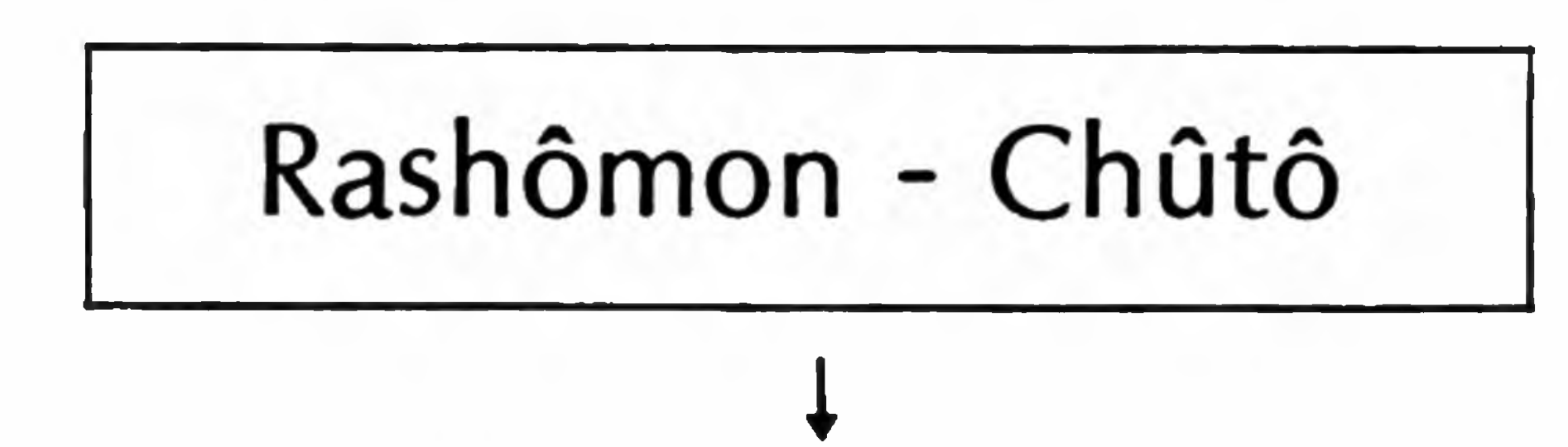

- Identificação homem-animal

- Ambiente negro, fétido, mórbido $\downarrow$

utilização de animais

(maior importância)

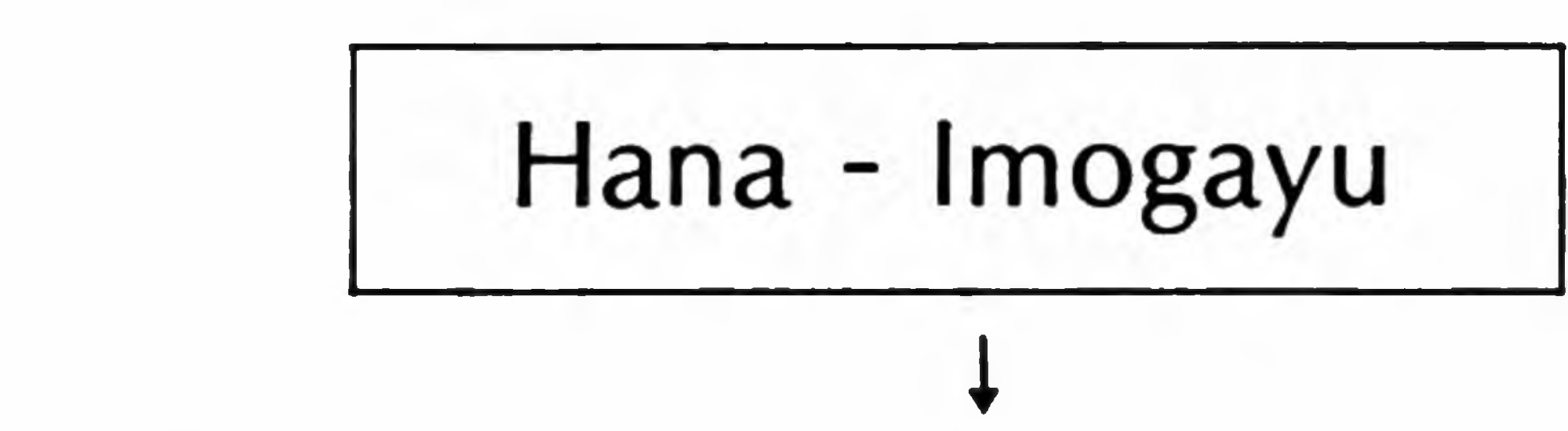

- Problemas do homem $\mathrm{x}$ homem

utilização de animais

(menor importância)

Vistos separadamente, notamos ainda a semelhança entre $\underline{\boldsymbol{R} a \boldsymbol{a} h \hat{\boldsymbol{o}}-}$ mon e Chûtô. Como já foi citado anteriormente, ambos estão dentro do mesmo tempo, espaço e ambiente e ambos focalizam a hesitação humana ante um grave problema: tornar-se ou não ladrão ( $\underline{\text { Rashômon }}$ ), matar ou não $(\underline{\text { Chûtô }})$. Roubar seria transgredir a moralidade, mas se não o fi-

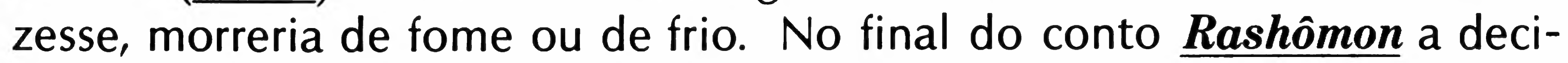
são do personagem é firme: torna-se ladrão. Pode-se notar aqui o pro- 
blema da relatividade da verdade: o que dentro de certas circunstâncias é considerado impugnável, em outras é considerado necessário e aceito.

Em Chûtô o matar surge como uma solução para garantir a união fraternal que existe entre Tarô e Jirô. Assim, a quebra ou não dos laços fraternais é resolvida da maneira tradicional: a princípio é abalado pela influência negativa de terceiros mas no fim o "sangue grita mais alto"

É em Hana que encontramos o menor número de comparações com animais. E é exatamente este o conto que se distancia mais dos outros naquilo que se refere à realidade do fato apresentado, isto é, comparado com os outros contos este apresenta características mais fictícias: o caso de um ladrão ou de um triângulo amoroso aproxima-se muito mais da realidade do que o caso do indivíduo que enfrenta o problema de variação do tamanho do seu nariz. Como já disse anteriormente, o próprio personagem é uma figura fora do comum (fisicamente) e o autor não necessitaria de comparações com animais para caracterizá-lo.

Em Imogayu é colocado em evidência a personalidade do protagonista e aqui, como seria de se esperar, as comparações com animais dizem respeito não tanto à sua descrição física, mas sim à sua maneira de ser, à impressão que a sua aparência causa aos outros.

Sabemos que a utilização de animais não é algo particular ou exclusivo de Akutagawa, mas, pelo menos nos quatro contos aqui vistos, podemos afirmar que este recurso foi aproveitado de maneira adequada e hábil. Isso ressalta, mais uma vez, a capacidade criadora deste renomado escritor.

\section{BIBLIOGRAFIA}

EBII, Eiji. Chûtôeno isshikaku. In: Akutagawa Ryûnosuke II Nihonbungaku Kenkyûshiryô Sôsho. Tóquio, Yûseidô, 1977.

HIRAOKA, Toshio. Akutagawani okeru rekishi shôsetsukara gendaimonoe - Jojôno henkaku. In: Akutagawa Ryûnosuke I - Nihonbungaku Kenkyûshiryô Sôsho. Tóquio, Yûseidô, 1973.

ISHIWARI, Tôru. Akutagawa Ryûnosuke no Rekishi Shôsetsu - Jisseikatsutono kanrennioite. In: Akutagawa Ryûnosuke II Nihonbungaku Kenkyûshiryô Sôsho. Tóquio, Yûseidô, 1977.

KUME, Masao. Hanato Akutagawa Ryûnosuke. In: Akutagawa Ryûnosuke II Nihonbungaku Kenkyûshiryô Sôsho. Tóquio, Yûseidô, 1977.

YAMAMOTO, Kenkichi. Akutagawato Ôgai - Rekishi Shôsetsuo Chûshinto shite. In: Akutagawa Ryûnosuke I Nihonbungaku Kenkyûshiryô Sôsho. Tóquio, Yûseidô, 1973.

YOSHIDA, Seiichi. Akutagawa Ryûnosuke. Tóquio, Kadokawashoten, 1967. 